tions. Yield-trial results during the first twelve years indicated that about a third of the lines selected were worthless, while the remainder were not significantly better or worse than samples of their parent varieties. Improvement in uniformity was obtained, and it was concluded that the method might have some use in re-selecting contaminated stocks. Intervarietal crosses were made between the various swede types, and lines were selected which were also propagated by selfing. It was considered that these lines tended to become too uniform in their genetic constitution, so that after four generations it was difficult to effect any improvement in type or in performance. The intensity of inbreeding is now being lessened by intercrossing related phenotypes and by propagating one or more of the early generations as groups of mother plants in isolation. Selection for clubroot resistance is also being carried out on young plants grown in boxes of infected soil.

Investigations with sugar beet have been in progress for only three seasons. The yield of this crop in Scotland might be increased by sowing a few weeks before mid-April ; but bolting would then become a serious consideration. Non-bolting sugar beet material under course of development at the Cambridge Plant Breeding Institute is being tested, and further selection and propagation is being carried out in collaboration with that Institute. A trial which included bolting and non-bolting material was demonstrated by Dr. Davey and Mr. F. J. W. England.

\section{FIFTH INTERNATIONAL ANATOMICAL CONGRESS, 1950}

T HE Second World War was responsible for the cancellation of the Fifth International Anatomical Congress, which had been arranged to take place in Great Britain in 1940, and not until this year was it found possible to hold it. The previous Congress was in 1936 in Milan, so that another international meet. ing was much overdue; and thus the Fifth Congress was held in Oxford during July 25-28, under the auspices of the Anatomical Society of Great Britain and Northern Ireland, with Prof. W. E. Le Gros Clark as president.

Altogether, thirty-six countries were represented at the Congress, but, with the exception of Jugoslavia, which sent three members, there was no representation of any of the Eastern European countries. Even so, the 535 members who eventually came constituted a record attendance. A Government reception was held in Christ Church prior to the opening session, and the members were welcomed on behalf of the Government by Viscount Addison, who before leaving academic life was himself a professor of anatomy. In his presidential address the next day, Prof. Le Gros Clark reviewed current trends in the study of anatomy, and, among other things, emphasized the thinness of the largely artificial barrier between anatomy and physiology ; his speech has been published in the British Medical Journal (ii, $233 ; 1950$ ). At the University Convocation which followed the opening plenary session, honorary degrees were conferred on Lord Addison, Prof. G. W. Corner (Baltimore), Prof. M. W. Woerdeman (Amsterdam) and Dr. L. S. B. Leakey (Nairobi).

The subject-matter of the scientific sessions reflected the wide range of interests of modern anatomists, and emphasized the fundamental nature of the study of anatomy in relation to other biological subjects. Indeed, so varied was the content of the two hundred or so communications that it is difficult to make any useful summary ; no official proceedings of the Congress are to be published. An attempt was made at rough classification into several groups: general anatomy, physical anthropology, neurology, histology, embryology and morphogenesis, and endocrinology ; and, so far as possible, papers with related subjectmatter were grouped together. This did not, however, prevent some strange juxtapositions. Thus, a paper on the mechanism of the interphalangeal joints in man was followed by one on the structure of the integument of the Anura; and a radiographic study of the mechanism of deglutition was succeeded by some remarks on the weak points of the lumbar region in Brazilian Indians.

In the section on neurology, which contained the greatest number of communications, there were two main groups, the first on the central nervous system, and the second on the peripheral nervous system and neurohistology. In addition, the greater part of two sessions concerned the peripheral parts of the autonomic system. The section on physical anthropology produced a spirited controversy regarding the origin and relationships of the Australopithecinæ, the observational evidence finding itself in conflict with the results of the more narrowly statistical approach. Among the other papers in this section were two dealing with the results so far obtained by the British-Kenya Miocene expedition. Under the heading of histology came several papers dealing with the application of phase-contrast microscopy to anatomical problems, and one whole session was devoted to papers dealing with bone. A number of new techniques were discussed, among them the use of microradiography and autoradiography. The section on embryology and morphogenesis included papers on experimental embryology and embryonic physiology as well as more purely descriptive papers. Lastly, in the endocrinology section, the main topics were the blood supply and functions of the pituitary and recent experimental work on the suprarenal cortex.

There were more than ninety demonstrations, involving some four hundred microscopes, and these, too, were roughly grouped together under headings. Here again, neurology was the heading under which came the greatest number of entries. Several films were shown, dealing with such diverse subjects as the tissue culture of osteoclasts and the recovery of skilled movements in monkeys after lesions in the motor cortex. An ad hoc discussion took place on the use of films in the teaching of normal anatomy, and in view of the difficulty, stressed by some Continental speakers, of obtaining material for dissection, it appears certain that there is scope for more and better teaching-films. The Congress resolved to form an international committee to approach the various and diverse sources known to be in possession of such films with the view to the formation of an international catalogue of available teaching material, and possibly the formation of a lending library.

It was also agreed to set up another committee, composed of delegates from the various national anatomical societies, to consider the difficult subject of modifying the present policy of laisser-faire with regard to anatomical terminology. The situation now is almost one of tot homines, quot sententice, since almost every nation has its own variant, usually, but 
not invariably, stemming from the great Basle Nomina Anatomica of the early years of this century. Any attempt to produce uniformity is, however, fraught with considerable danger, since anatomical terminology enters into many fields of research and classification; and it was felt that great care must be exercised before deciding to inflict any changes on the long-suffering clinicians, who in many cases have already probably had to master at least three different terminologies. It was also agreed, however, that the subject is one of such importance that an approach should be made to the United Nations Educational, Scientific and Cultural Organisation for the purpose of appointing a paid secretary to the committee.

The Congress coincided happily with an exhibition in the Radcliffe Science Library reviewing the history of the teaching of anatomy at Oxford, and a booklet on this subject was presented to each member. The official languages of the Congress were English, French, German, Spanish and Italian, and the interpreters were kept busy. For the most part the delegates were accommodated in Oxford colleges, and during their visit there was no lack of entertainment. Many members took part in sightseeing tours and visits to places of interest; on the last night there was a dance at Oriel College, which was well attended. There was plenty of opportunity for the exchange of informal views and speculations between members who had not seen each other for many years, and the fullest possible use was made of it.

At the closing plenary session, the president referred to the death of Prof. H. C. Bazett, of the University of Pennsylvania, on his way to attend the Congress. It was proposed by Prof. J. Benoit, on behalf of the Association des Anatomistes de Langue Française, that the Sixth International Anatomical Congress should be held under the auspices of the Association, probably in Algiers, in 1955. This invitation was cordially accepted by the members, as was the proposal of Prof. N. L. Hoerr that the American Association of Anatomists should be responsible for the succeeding Congress. The members then dispersed, many of them to pay visits to other laboratories in Great Britain, and all having enjoyed a very pleasant and stimulating few days.

\section{FLUORESCENT INKS FOR ADVERTISEMENT POSTERS}

T

HE use in Great Britain in recent months of unusually brilliant coloured inks on advertisement posters has excited a good deal of interest and comment-some favourable and some otherwise. If, however, it be the purpose of a poster to invite attention, then these inks must be regarded as a success.

The underlying principle of the special inks used for these posters is that they contain a daylight fluorescent pigment which, because it fluoresces in the visible range, imparts the brilliance of colour. The fluorescent pigment is made by dissolving a small quantity of a fluorescent dyestuff in a transparent thermosetting resin (urea formaldehyde or phenol formaldehyde) and grinding the solid solution to a coarse powder. This pigment is then incorporated in a special printing ink containing coloured pigment and oil. Because fine grinding - the usual method of incorporating pigments in oil-destroys the fluorescent properties of the pigment, it is necessary that special inks be used, suitable only for a printing process known as 'silk screen printing'. The usual printing processes used for poster production-lithography and letterpress-demand finely ground inks, and for this reason the fluorescent inks cannot be used. Another reason for using the silk screen process is that it applies a much thicker film of ink to the paper than either lithography or letterpress, and this is an advantage, since the fluorescent inks are not 'permanent'. Even the best of the inks lose their effect after exposure for a month or so. Within limits, however, the thicker the ink film the more permanent is the ink, and hence the desire to print as much ink as possible.

The silk screen process has been used for a number of years for producing posters, showcards, folders, etc., where the number of copies is comparatively few ; but the introduction of the new inks has extended the scale of operation considerably. The process is, in effect, a stencil printing process in which a thin inkmore like a paint than a normal printing ink-is forced through the mesh of $\mathbf{a}$ stencil made from $\mathbf{a}$ piece of silk stretched over a frame (synthetic fibres and wire mesh are also used). The stencil is made either by photographic means or is hand-prepared. The meshes in the image areas are left open, while those of the non-image areas are filled in. $A$ stencil is made for each colour to be printed, and the ink is forced through the silk by means of a squeegee on to the sheet of paper beneath. Although the process can be made semi-automatic, a good deal of hand operation is involved, and hence to produce a large number of impressions is comparatively expensive.

The original patents covering these inks are American, and most of the inks used up to now have been of United States origin. The majority of ink makers in Great Britain, and on the Continent of Europe, are investigating their manufacture. The colours available to date are at the longer end of the spectrum-the reds, yellows and yellow-greens.

\section{CENTRAL GLASS AND CERAMIC RESEARCH INSTITUTE OF INDIA}

$\mathrm{T}$ HE official opening of the Central Glass and Ceramic Research Institute of India at Calcutta by the Honourable Dr. B. C. Roy, Chief Minister, Government of West Bengal, on August 26, brings to fruition a well-planned scheme launched by the Council of Scientific and Industrial Research in India and removes the long-felt and urgent need for the establishment of such an institution in India. This is the fourth laboratory established by the Council to be declared open-the other three being the National Chemical Laboratory at Poona, the National Physical Laboratory at Delhi and the Fuel Research Institute at Dhanbad.

An account of the plans for this latest research institute was given in Nature of March 1, 1947. Although the foundation stone of the Institute was laid on December 24, 1945, by the late Sir Ardeshir Dalal, then member of the Viceroy's Executive Council in charge of the Department of Planning and Development, it was impossible to start work until September 1948. Only the technological block had 